\title{
PENGARUH ENTREPRENEURIAL COMPETENCIES TERHADAP KEUNGGULAN BERSAING SERTA IMPLIKASINYA TERHADAP KINERJA WIRAUSAHA (Studi Kasus pada Usaha Konveksi KUBE “Maju Bersama” Kota Salatiga)
}

\author{
Oleh : \\ Mada Adi Wibowo ${ }^{1}$, Yanuar Surya Putra ${ }^{2}$ \\ STIE AMA Salatiga \\ mada.adi.wibowo@gmail.com
}

\begin{abstract}
The purpose of this research is to examine the effect of entrepreneurial competencies advantage and its implications for entrepreneurial performance. In this study competitive advantage is also positioned as an intervening variable that mediates the influence of entrepreneurial competence on entrepreneurial performance.

The population in this study are SMEs who are member of KUBE Maju Bersama in Salatiga totaling 30 people. The sampling technique use is saturated sampling so that the sample size is the same as rhe population. Data collection method use survey methods and data analysis techniques using path analysis.

The result showed that entrepreneurial competencies did not have a significant influence on competitive advantage did not mediate the influence of entrepreneurial competencies towards entrepreneurial performance. So it can be concluded that the entrepreneurial competencies possesed by SMEs members in KUBE Maju Bersama have not a significant direct influence on improving the entrepreneurial performance of KUBE Maju Bersama
\end{abstract}

Keywords : Entrepreneurial Competencies, Competitive Advantages, Entrepreneurial Performances.

\section{PENDAHULUAN}

Pengembangan kewirausahaan beberapa tahun terakhir memang telah menjadi isu lembaga-lembaga ekonomi mulai dari tingkat daerah, nasional bahkan internasional. Kecenderungan ini karena keyakinan bahwa kewirausahaan adalah kunci untuk sejumlah hasil-hasil sosial yang diinginkan, termasuk pertumbuhan ekonomi, pengangguran yang lebih rendah, dan modernisasi teknologi (Baumol, et al. 2007). Jumlah wirausaha di Indonesia sangat sedikit padahal kewirausahaan sangat dibutuhkan untuk perkembangan dan kemajuan ekonomi sebuah negara. Usaha Mikro, Kecil, dan Menengah (UMKM) merupakan sektor yang amat vital sebagai penyangga ekonomi daerah dalam menciptakan pertumbuhan dan lapangan pekerjaan. Namun, pentingnya sektor ini belum diimbangi dengan kontribusi terhadap nilai Produk Domestik Bruto (PDB) dan nilai ekspor yang relatif masih rendah bila dibandingkan dengan populasi pelaku UMKM sebanyak 99,9\% (Bank Indonesia, 2015).

Selain itu, kultur UMKM yang tidak profesional menjadi kendala tersendiri bagi peningkatan kualitas SDM. Disamping kondisi yang dihadapi oleh UMKM dengan latar belakang pendidikan pelaku UMKM rendah, sehingga sulit memahami atau menguasai tentang cara meningkatkan kualitas dan standarisasi produk, memperluas dan meningkatkan akses pembiayaan, memperkuat dan meningkatkan akses teknologi untuk pengembangan UMKM, meningkatkan akses promosi di dalam dan luar negeri, dan membangun jejaring bisnis global.

Pengertian Kewirausahaan menurut Suryana (2003) adalah kemampuan kreatif dan inovatif yang dijadikan dasar, kiat dan sumber daya untuk mencari peluang menuju sukses.

Dalam literatur Manajemen, konsep kompetensi telah banyak di diskusikan dan dibahas melalui berbagai persepektif khususnya dalam lingkup organisasi. Menurut Boyatzis dalam Mitchelmore dan Rowley (2010) bagi suatu organisasi, kompetensi merupakan salah satu faktor penentu keberhasilan organisasi tersebut, karena kompetensi merupakan nilai - nilai personal, pengetahuan, skill dan motif yang dimiliki oleh seseorang atau organisasi yang dapat mendorong kinerja yang maksimal. Kompetensi tidak hanya dapat diartikan sebagai cara bagaimana suatu organisasi dapat mencapai tujuannya namun lebih daripada itu kompetensi merupakan learning process yang harus terus di lakukan oleh suatu organisasi. 
Inti dari kewirausahaan adalah kemampuan untuk menciptakan sesuatu yang baru dan berbeda (create new and different) melalui berfikir kreatif dan inovatif. Menurut Wahyono (2002) tujuan utama dari inovasi dalam konteks perusahaan adalah untuk memenuhi permintaan pasar sehingga produk inovasi merupakan salah satu yang dapat digunakan sebagai keunggulan bersaing bagi perusahaan. Gray et al (2002) juga mengemukakan bahwa kemampuan inovasi dari suatu perusahaan akan menjamin kemampuan bersaing perusahaan. Pada umumnya pelanggan menginginkan produk yang inovatif sesuai dengan keinginan mereka. Sementara itu bagi perusahaan, keberhasilan dalam melakukan inovasi produk berarti perusahaan tersebut selangkah lebih maju dibandingkan pesaingnya (Supranoto, 2009).

Konsep keunggulan bersaing banyak dikembangkan dari strategi generik yang dikemukakan Porter (1985). Ajaran Porter tentang strategi generik untuk keunggulan bersaing terdiri dari keunggulan biaya, differensiasi dan fokus. Lumpkin dan Dess (2005) menyatakan bahwa sebuah keunggulan kompetitif ada ketika pelanggan merasakan bahwa produk yang dimiliki perusahaan memiliki kelebihan dari pesaingnya. Adner dan Zemsky (2006), perspektif keunggulan bersaing yang mempertimbangkan perspektif berbasis permintaan. Keunggulan bersaing dapat dilihat dari tingkat kepentingan kualitas terhadap pasar dan mengklasifikasikan ke dalam 4 (empat) tipe sumber daya dalam penciptaan nilai, yaitu proses sumber daya untuk menurunkan struktur biaya, sumber daya produk untuk meningkatkan kinerja, sumber daya waktu untuk menghantarkan nilai sesuai waktu pasar, dan sumber daya inovasi untuk mempengaruhi teknologi.

Perlunya pengujian Entrepreneurial Competencies terhadap pelaku wirausaha nantinya mampu mengidentifikasi kompetensi apa yang harus ditingkatkan guna menunjang perkembangan usahanya melalui keunggulan bersaing. Dalam penelitian ini kelompok wirausaha yang menjadi obyek penelitian adalah Kelompok Usaha Bersama (KUBE) Maju Bersama merupakan sebuah kelompok usaha yang berlokasi di Desa Tingkir Tengah dan Tingkir Lor, Kecamatan Tingkir, Kota Salatiga, yang berdiri pada tanggal 22 Juni 2013. Jenis usahanya adalah berupa pengolahan sisa kain dari pabrik tekstil, yakni kain perca yang nantinya akan dijadikan produk berupa baju, jaket, celana santai, tas dan sandal. Desa Tingkir Tengah dan Tingkir Lor memang terkenal dengan sentra konveksinya, atas potensinya tersebut Pemerintah Kota Salatiga bermaksud mengembangkan desa tersebut menjadi "desa wisata".

\section{TINJAUAN PUSTAKA}

\section{1) Entrepreneurial Competencies}

Konsep dalam penelitian ini adalah Entrepreneurial Competencies. Entrepreneurial Competencies diidentifikasikan sebagai sekumpulan kompetensi yang relevan untuk mengembangkan kewirausahaan. Man (2002) mengungkapkan bahwa Entrepreneurial Competencies merupakan keseluruhan kemampuan yang dimiliki oleh wirausahawan untuk dapat menunjukkan perannya dalam mengembangkan usahanya. Menurut Bird (1995) mengungkapkan bahwa Entrepreneurial competencies harus dimiliki oleh wirausahawan dan kompetensi ini sudah harus dimiliki sejak awal berdirinya usaha, selain itu orang - orang yang terlibat dalam pengembangan usaha juga harus memiliki kompetensi ini. Hasil penelitian Bird (1995) juga menunjukkan bahwa Entrepreneurial Competencies juga sama pentingnya dengan Managerial Competencies, dan Entrepreneurial Competencies merupakan kompetensi dapat digunakan oleh wirausahawan sebagai dasar untuk mengembangkan usahanya menjadi lebih besar.

\section{2) Keunggulan Bersaing}

Konsep keunggulan bersaing banyak dikembangkan dari strategi generic yang dikemukakan Porter (1985). Ajaran Porter tentang strategi generik untuk keunggulan bersaing terdiri dari keunggulan biaya, differensiasi dan fokus kepada pelanggan masih relevan untuk tetap digunakan. Keunggulan bersaing adalah jantung kinerja perusahaan dalam persaingan pasar. Keunggulan bersaing pada dasarnya tumbuh dari nilai atau manfaat yang dapat diciptakan perusahaan bagi pembelinya. Bila perusahaan kemudian mampu menciptakan keunggulan melalui salah satu dari ketiga strategi generik yang dikemukakan oleh Porter tersebut, maka akan didapatkan keunggulan bersaing (Aaker, 1989).

Menurut Mangkuprawira (2007), dua prinsip pokok yang perlu dimilikiperusahaan untuk meraih keunggulan kompetitif yaitu adanya nilai pandang pelanggan dan keunikan produk. (1). Sudut Pandang Nilai PelangganKeunggulan kompetitif terjadi apabila terdapat pandangan pelanggan bahwa mereka memperoleh nilai tertentu dari transaksi ekonomi denganperusahaan tersebut. Untuk itu syaratnya adalah semua karyawan perusahaan harus fokus pada kebutuhan dan harapan pelanggan. Hal demikian baru terwujud ketika pelanggan dilibatkan dalam merancang proses memproduksi barang dan atau jasa serta didorong membantu 
perusahaan merancang sistem MSDM yang akan mempercepat pengiriman barang dan jasa yang diinginkan pelanggan. (2) Sudut Keunikan Keunikan dicirikan oleh barang dan jasa yang dihasilkan perusahaan tidak dapat mudah ditiru oleh pesaing.

(Rizky, 2015, p. 29) Strategi bersaing generik yang diterapkan pada level unit usaha strategis atau produk (dan jasa) yang dihasilkan perusahaan terdiri dari tiga macam, yakni : strategi keunggulan biaya, diferensiasi dan fokus.

a. Strategi keunggulan biaya

Strategi biaya rendah (cost leadership) menekankan pada upaya memproduksi produk standar (sama segala aspek) dengan biaya per unit yang sangat rendah.

b. Diferensiasi (Rizky, 2015, p. 30) dalam strategi diferensiasi dibutuhkan kemampuan perusahaan untuk dapat menarik, memiliki dan mempertahankan sumber daya yang tidak hanya cerdas tetapi juga kreatif dan kadang kala membutuhkan dukungan gaya manajerial dan insentif yang khas.

c. Fokus (Rizky, 2015, p. 30) strategi fokus digunakan untuk membangun keunggulan bersaing dalam suatu segmen pasar yang lebih sempit. Strategi jenis ini ditujukan untuk melayani kebutuhan konsumen yang jumlahnya relatif kecil dan dalam pengambilan keputusannya untuk membeli relatif tidak dipengaruhi harga.

3) Entrepreneurial Competencies dan Kinerja Wirausaha

Dalam konteks wirausaha kompetensi merupakan bagian yang tidak dapat dipisahkan dari usaha tersebut mulai dari terbentuknya sampai dengan pertumbuhan usaha tersebut (Bird, 1995; Baum et al, 2001; Colombo and Grilli, 2005). Penelitian sebelumnya menunjukkan bahwa keahlian entrepreneurship memberikan kontribusi terhadap kinerja maupun pertumbuhan usaha (Lerner and Almor, 2002; Bird, 1995; Cooper and Gimeno-Gascon, 1994). Lebih lanjut penelitian telah membuktikan bahwa pengembangan keahlian entrepreneurial bagi wirausahawan memberikan kontribusi terhadap keuntungan dan pertumbuhan usaha (Chandler and Jensen, 1992).

4) HIPOTESIS

Hipotesis merupakan dugaan yang akan diuji kebenarannya dengan fakta yang ada (Jogiyanto,2004:41). Hipotesis dalam penelitian ini adalah :

1) H1 = Entrepreneural Competencies berpengaruh terhadap Keunggulan Bersaing di KUBE "Maju Bersama"

2) H2 = Keunggulan Bersaing berpengaruh terhadap Kinerja Wirausaha di KUBE "Maju Bersama"

3) $\mathrm{H}_{3}=$ Entrepreneurial Competencies berpengaruh terhadap Kinerja Wirausaha di KUBE "Maju Bersama"

\section{METODOLOGI PENELITIAN}

\section{1) Data}

Ada 2 jenis data yang dipergunakan dalam penelitian ini, yaitu data primer dan sekunder. Secara singkat, data primer adalah data yang dikumpulkan dan diolah oleh peneliti secara langsung dari responden. Sedangkan, data sekunder adalah data yang diperoleh secara tidak langsung antara lain dengan memanfaatkan data yang telah diolah seperti laporan,dokumen, statistik dan literatur-literatur yang mendukung dalam penulisan ini.

\section{2) Populasi dan Sampel}

Populasi dalam penelitian ini adalah anggota dari KUBE "Maju Bersama" yang berjumlah 30 anggota. Semua anggota populasi akan dijadikan sampel penelitian ( Saturated Sample ).

3) Variabel

Variabel penelitian adalah konsep abstrak yang dapat diukur (Ghozali, 2013 : 11). Penelitian ini memiliki 3 jenis variabel, sebagai berikut:

1. Variabel Independen : Entrepreneural Competencies (X)

2. Variabel Intervening : Keunggulan Bersaing (Y1)

3. Variabel Dependen : Kinerja Wirausaha (Y2)

\section{5) PEMbahasan}

\section{1) Uji Validitas}

Uji validitas digunakan untuk mengukur tingkat ketepatan suatu instrumen dalam kuesioner. Hasil pengulangan uji validitas menunjukkan bahwa nilai $r$ hitung antara jawaban responden di setiap butir pertanyaan dengan nilai total jawaban responden 
menghasilkan nilai $r$ hitung > dari $r$ tabel $(0,410-0,901>0,361)$ sehingga ketiga variabel dinyatakan valid.

\section{2) Uji Reliabilitas}

Pengujian keandalan dalam penelitian ini dilakukan dengan alat analisis scale yang ditunjukkan oleh nilai alpha cronbach > 0,7. Berdasarkan hasil uji reliabilitas dengan menggunakan SPSS sebagaimana tabel diatas, menunjukkan bahwa nilai alpha hitung lebih besar dari alpha tabel yaitu $0,70(0,757-0,805>0,7)$. Dengan demikian, semua variabel- variabel yang digunakan dalam penelitian ini reliabel, sehingga dapat terus digunakan untuk analisis selanjutnya.

\section{3) Uji Model}

Uji model dilakukan digunakan untuk melihat baik atau tidaknya model regresi yang digunakan. Pengujian dilakukan berdasarkan koefisien determinasi dan uji $-\mathrm{F}$.

\section{a. Koefisien Determinasi}

Uji fit model regresi dapat dilakukan berdasarkan nilai koefesien determinasi yaitu melihat kemampuan variabel independen didalam menjelaskan variabel dependen. Nilai koefisien determinasi Entreprenurial Competencies dan Keunggulan Bersaing terhadap Kinerja Wirausaha dapat dilihat pada tabel 7.Tabel 7.1

\section{Koefisien Determinasi}

Entreprenurial Competencies dan Keunggulan Bersaing

Terhadap Kinerja Wirausaha

Model Summary

\begin{tabular}{|l|r|r|r|r|}
\hline Model & \multicolumn{1}{|c|}{$\mathrm{R}$} & R Square & \multicolumn{1}{|c|}{$\begin{array}{c}\text { Adjusted R } \\
\text { Square }\end{array}$} & $\begin{array}{c}\text { Std. Error of the } \\
\text { Estimate }\end{array}$ \\
\hline 1 &, $738^{\mathrm{a}}$ &, 545 &, 511 & 1,785 \\
\hline
\end{tabular}

a. Predictors: (Constant), Keunggulan Bersaing, Entrepreneurial Competencies

Sumber : Data Primer Diolah (2018)

Besarnya koefisien determinasi dapat dilihat pada nilai $R$ Square sebesar 0,545. Hasil ini dapat diartikan Entreprenurial Competencies dan Keunggulan Bersaing mempengaruhi Kinerja Wirausaha sebesar 54,5\% (0,545 x $100 \%$, sementara itu 45,5\% (100\%-54,5\%) Kinerja Waryawan dipengaruhi oleh faktor selain Entreprenurial Competencies dan Keunggulan Bersaing. Dengan nilai koefisien determinasi yang mendekati nilai satu berarti model regresi Entreprenurial Competencies dan Keunggulan Bersaing terhadap Kinerja Wirausaha termasuk fit atau baik.

\section{b. Uji - F}

Uji kelayakan model juga dapat dilakukan dengan menggunakan uji $-\mathrm{F}$, yaitu melihat pengaruh variabel independen terhadap variabel dependen secara simultan (bersama-sama). Adanya pengaruh secara simultan yaitu nilai sig. $\leq \alpha=$ 0,05 maka model regresi dinyatakan fit atau baik.

Hasil uji - F Entrepreneurial Competencies dan Keunggulan Bersaing terhadap Kinerja Wirausaha dapat dilihat pada tabel 7

Tabel 7.2

$\mathrm{Uji}-\mathrm{F}$

Entrepreneurial Competencies dan Keunggulan Bersaing

ANOVA $^{\mathrm{a}}$

\begin{tabular}{|c|c|c|c|c|c|c|}
\hline Model & & Sum of Squares & Df & Mean Square & $\mathrm{F}$ & Sig. \\
\hline \multirow{3}{*}{1} & \multirow{3}{*}{$\begin{array}{l}\text { Regression } \\
\text { Residual } \\
\text { Total }\end{array}$} & 102,899 & 2 & 51,449 & 16,140 &, $000^{\mathrm{b}}$ \\
\hline & & 86,068 & 27 & 3,188 & & \\
\hline & & 188,967 & 29 & & & \\
\hline
\end{tabular}

a:. Dependent Variable: KInerja Wirausaha

b. Predictors: (Constant), Keunggulan Bersaing, Entrepreneurial Competencies 
Sumber : Data Primer Diolah (2018)

Hasil uji - F mendapatkan nilai sebesar 16,140 dengan sig.0,000 $<\alpha=0,05$. Dengan hasil ini maka Entrepreneurial Competencies dan Keunggulan Bersaing berpengaruh signifikan terhadap Kinerja Wirausaha secara simultan (bersama-sama), sehingga model regresi yang digunakan dinyatakan fit atau baik.

\section{4) Hasil Analisis Regresi}

Teknik analisis yang digunakan dalam penelitian ini yaitu analisis jalur (Path Analysis). Analisis ini digunakan untuk mengetahui pengaruh variabel independen terhadap variabel dependen yang dimediasi oleh variabel lain. Pada penelitian ini akan dilihat pengaruh Entrepreneurial Competencies terhadap Kinerja Wirausaha yang dimediasi oleh Keunggulan Bersaing. Berikut ini hasil-hasil regresi yang digunakan untuk pengujian dengan teknik analisis Jalur.

1) Hasil analisis regresi Entrepreneurial Competencies terhadap Keunggulan Bersaing dapat dilihat hasilnya pada tabel 7.3

Tabel 7.3

Hasil Regresi

Entrepreneurial Competencies Terhadap Keunggulan Bersaing

Coefficients ${ }^{a}$

\begin{tabular}{|c|c|c|c|c|c|c|}
\hline \multirow[t]{2}{*}{ Model } & & \multicolumn{2}{|c|}{ Unstandardized Coefficients } & \multirow{2}{*}{$\begin{array}{c}\text { Standardized } \\
\text { Coefficients } \\
\text { Beta }\end{array}$} & \multirow[t]{2}{*}{$\mathrm{t}$} & \multirow[t]{2}{*}{ Sig. } \\
\hline & & B & Std. Error & & & \\
\hline & (Constant) & 26,480 & 5,641 & & 4,694 &, 000 \\
\hline 1. & $\begin{array}{l}\text { Entrepreneurial } \\
\text { Competencies }\end{array}$ &,- 143 & ,412 &,- 065 &,- 347 & ,731 \\
\hline
\end{tabular}

a. Dependent Variable: Keunggulan Bersaing

Sumber : Data Primer Diolah (2018)

Nilai koefisien regresi dapat dilihat pada standardized coefficients dan berdasarkan dari nilai koefisien tersebut dapat dibuat persamaan sebagai berikut :

$\mathrm{Y} 1=-0,065 \mathrm{X}+\mathrm{e} 1$

Persamaan regresi tersebut dapat dartikan Koefisien regresi Entrepreneurial Competencies (b1) negatif sebesar 0,065. Hal ini berarti setiap ada peningkatan Entrepreneurial Competencies akan menurunkan Keunggulan Bersaing.

2) Hasil analisis Entrepreneurial Competencies dan Keunggulan Bersaing terhadap Kinerja Wirausaha dapat dilihat hasilnya pada tabel 7.4 
Tabel 7.4

Hasil Regresi Entrepreneurial Competencies dan Keunggulan Bersaing

Terhadap Kinerja Wirausaha

\section{Coefficients ${ }^{a}$}

\begin{tabular}{|c|c|c|c|c|c|c|}
\hline \multirow[t]{2}{*}{ Model } & & \multicolumn{2}{|c|}{ Unstandardized Coefficients } & \multirow{2}{*}{$\begin{array}{c}\text { Standardized } \\
\text { Coefficients } \\
\text { Beta }\end{array}$} & \multirow[t]{2}{*}{$\mathrm{t}$} & \multirow[t]{2}{*}{ Sig. } \\
\hline & & $\mathrm{B}$ & Std. Error & & & \\
\hline & (Constant) & 26,480 & 5,641 & & 4,694 &, 000 \\
\hline 1 & $\begin{array}{l}\text { Entrepreneurial } \\
\text { Competencies }\end{array}$ &,- 143 & ,412 &,- 065 &,- 347 & ,731 \\
\hline
\end{tabular}

a. Dependent Variable: KInerja Wirausaha

Sumber : Data Primer Diolah (2018)

Nilai koefesien regresi dapat dilihat pada standardized coefficients dan berdasarkan dari nilai koefisien tersebut dapat dibuat persamaan sebagai berikut:

$\mathrm{Y}_{2}=0,000 \mathrm{X}+0,738 \mathrm{Y}_{1}+\mathrm{e}_{2}$

Persamaan regresi tersebut dapat dartikan sebagai berikut :

a. Koefisien regresi Entrepreneurial Competencies $\left(\mathrm{b}_{1}\right)$ positif sebesar 0,000.

Hal ini berarti setiap ada peningkatan Entrepreneurial Competencies akan meningkatkan Kinerja Wirausaha.

b. Koefisien regresi Keunggulan Bersaing $\left(b_{2}\right)$ positif sebesar 0,738. Hal ini berarti setiap ada peningkatan Keunggulan Bersaing akan meningkatkan Kinerja Wirausaha.

\section{5) Pengujian Hipotesis}

a. $\mathbf{U j i}-\mathbf{t}$

$\mathrm{Uji}-\mathrm{t}$ digunakan untuk membuktikan pengaruh variabel independen terhadap variabel dependen secara parsial (sendiri-sendiri). Hipotesis diterima apabila nilai sig. $\leq \alpha=0,05$.

1) Hasil uji - t Entrepreneurial Competencies terhadap kepuasan kerja dapat dilihat hasilnya pada tabel 7.5

Tabel 7.5. Hasil Uji - $\mathrm{t}$

Entrepreneurial Competencies Terhadap Keunggulan Bersaing

Coefficients $^{\mathrm{a}}$

\begin{tabular}{|c|c|c|c|c|c|c|}
\hline \multirow[t]{2}{*}{ Mode } & & \multicolumn{2}{|c|}{ Unstandardized Coefficients } & \multirow{2}{*}{$\begin{array}{c}\text { Standardized } \\
\text { Coefficients } \\
\text { Beta }\end{array}$} & \multirow[t]{2}{*}{$\mathrm{T}$} & \multirow[t]{2}{*}{ Sig. } \\
\hline & & B & Std. Error & & & \\
\hline \multirow{3}{*}{$1 \cdot$} & (Constant) &,- 748 & 4,333 & &,- 173 & ,864 \\
\hline & $\begin{array}{l}\text { Entrepreneurial } \\
\text { Competencies }\end{array}$ & ,001 & ,237 &, 000 & ,003 & ,998 \\
\hline & Keunggulan Bersaing & ,616 & , 109 & ,738 & 5,670 &, 000 \\
\hline
\end{tabular}

a. Dependent Variable: Keunggulan Bersaing

Sumber : Data Primer Diolah (2018) 
Berdasarkan dari hasil uji - $\mathrm{t}$ maka dapat dilakukan pengujian hipotesis sebagai berikut :

Hasil uji - t Entrepreneurial Competencies terhadap Keunggulan Bersaing sebesar -0,347 dengan sig. $0,731>\alpha=0,05$. Hal ini berarti menolak hipotesis ( $\left.\mathrm{Ha}_{1}\right)$ yang menyatakan Entrepreneurial Competencies berpengaruh terhadap Keunggulan Bersaing.

Man (2002) mengungkapkan bahwa Entrepreneurial Competencies merupakan keseluruhan kemampuan yang dimiliki oleh wirausahawan untuk dapat menunjukkan perannya dalam mengembangkan usahanya.

Pada penelitian di KUBE Maju Bersama Salatiga memperlihatkan bahwa rata-rata kemampuan berwirausaha tidak mampu mengembangkan usahanya untuk melakukan keunggulan bersaing. Hal ini dapat terlihat dari adanya Kemampuan dalam mengembangkan peluang, memimpin, menciptakan daya saing, komunikasi, komitmen \& respon cepat dalam menyelesaikan masalah kurang dimiliki oleh pelaku usaha konveksi KUBE Maju Bersama.

2) Hasil uji - t Entrepreneurial Competencies dan Keunggulan Bersaing Terhadap Kinerja Wirausaha dapat dilihat hasilnya pada tabel 7.6

Tabel 7.6

Hasil Uji - $\mathrm{t}$

Entrepreneurial Competencies dan Keunggulan Bersaing

Terhadap Kinerja Wirausaha

\begin{tabular}{|c|c|c|c|c|c|c|}
\hline \multirow[t]{2}{*}{ Mod } & & \multicolumn{2}{|c|}{$\begin{array}{l}\text { Unstandardized Coefficients } \\
\text { Coefficients }^{\mathbf{a}}\end{array}$} & \multirow{2}{*}{$\begin{array}{c}\text { Standardized } \\
\text { Coefficients } \\
\text { Beta }\end{array}$} & \multirow[t]{2}{*}{$\mathrm{t}$} & \multirow[t]{2}{*}{ Sig. } \\
\hline & & B & Std. Error & & & \\
\hline \multirow{3}{*}{1} & (Constant) &,- 748 & 4,333 & &,- 173 & ,864 \\
\hline & $\begin{array}{l}\text { Entrepreneurial } \\
\text { Competencies }\end{array}$ & ,001 & 237 & ,000 & ,003 & ,998 \\
\hline & Keunggulan Bersaing & ,616 & 109 & ,738 & 5,670 & ,000 \\
\hline
\end{tabular}

a: Dependent Variable: KInerja Wirausaha

Sumber : Data Primer Diolah (2018)

Berdasarkan dari hasil uji - $\mathrm{t}$ maka dapat dilakukan pengujian hipotesis sebagai berikut :

a) Hasil uji - t Keunggulan Bersaing terhadap Kinerja Wirausaha sebesar 5,670 dengan sig. 0,000< $\alpha=0,05$. Hal ini berarti menerima hipotesis $\left(\mathrm{Ha}_{2}\right)$ yang menyatakan Keunggulan Bersaing berpengaruh terhadap Kinerja Wirausaha. (Rizky, 2015, p. 29) Strategi bersaing generik yang diterapkan pada level unit usaha strategis atau produk (dan jasa) yang dihasilkan perusahaan terdiri dari tiga macam, yakni : strategi keunggulan biaya, diferensiasi dan fokus. Pada penelitian di KUBE Maju Bersama Kota Salatiga memperlihatkan bahwa rata-rata pelaku usaha konveksi melakukan kegiatan keunggulan bersaing mulai dari keunggulan produk, keunggulan pelayanan, keunggulan citra dan keunggulan biaya benar-benar dilakukan oleh pelaku usaha konveksi KUBE Maju Bersama Kota Salatiga.

b) Hasil uji - t Entrepreneurial Competencies terhadap Kinerja Wirausaha sebesar 0,003 dengan sig. $0,998>\alpha=0,05$. Hal ini berarti menolak hipotesis (Ha3) yang menyatakan Entrepreneurial 
Competencies berpengaruh terhadap Kinerja Wirausaha. Man (2002) mengungkapkan bahwa Entrepreneurial Competencies merupakan keseluruhan kemampuan yang dimiliki oleh wirausahawan untuk dapat menunjukkan perannya dalam mengembangkan usahanya.

Pada penelitian di KUBE Maju Bersama Kota Salatiga memperlihatkan bahwa rata-rata karyawan tidak memiliki Entrepreneurial Competencies yang tinggi dalam hasil berwirausaha atau Kinerja Wirausaha . Hal ini dapat terlihat dari Kemampuan dalam mengembangkan peluang, memimpin, menciptakan daya saing, komunikasi, komitmen \& respon cepat dalam menyelesaikan masalah kurang dimiliki oleh pelaku usaha konveksi KUBE Maju Bersama.

\section{6) Uji Analisis Jalur}

Uji analisis jalur digunakan untuk membuktikan apakah variabel Keunggulan Bersaing menjadi variabel yang memediasi antara Entrepreneurial Competencies terhadap Kinerja Wirausaha. Analisis dilakukan berdasarkan dari nilai standardized coefficients dari hasil regresi dan dapat dibuat analisis jalur sebagai berikut :

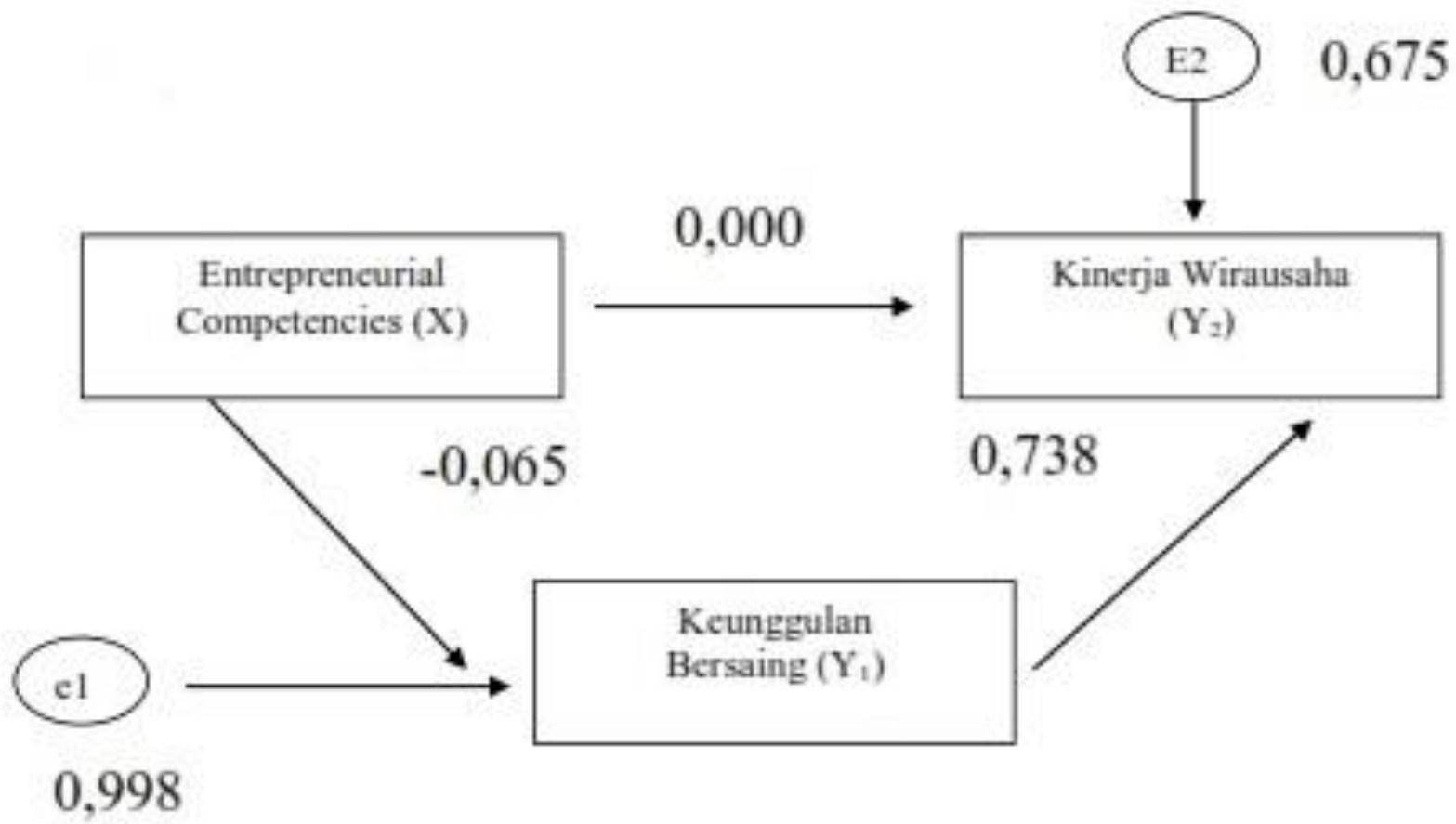

Gambar 7.1

Analisis Jalur Entrepreneurial Competencies Terhadap

Kinerja Wirausaha melalui Keunggulan Bersaing

Berdasarkan dari gambar analisis jalur maka dapat dianalisa sebagai berikut :

Analisis Jalur Entrepreneurial Competencies Terhadap Kinerja Wirausaha Melalui Keunggulan Bersaing

a) Pengaruh langsung Entrepreneurial Competencies terhadap Kinerja Wirausaha sebesar 0,000.

b) Pengaruh Entrepreneurial Competencies terhadap Keunggulan Bersaing sebesar -0,065dan pengaruh Keunggulan Bersaing terhadap Kinerja Wirausaha sebesar 0,738, dengan demikian pengaruh tidak langsung Entrepreneurial Competencies terhadap Kinerja Wirausaha melalui Keunggulan bersaing adalah sebesar -0,065 x 0,738 =-0,048

Hasil perhitungan menunjukkan pengaruh tidak langsung Entrepreneurial Competencies terhadap Kinerja Wirausaha melalui Keunggulan Bersaing lebih kecil dibanding pengaruh langsung Entrepreneurial Competencies terhadap Kinerja Wirausaha. 


\section{KESIMPULAN}

Kesimpulan penelitian mengenai Pengaruh Entrepreneurial Competencies Terhadap Keunggulan Bersaing serta Implikasinya Terhadap Kinerja Wirausaha (Studi Kasus pada Usaha Konveksi KUBE Maju Bersama Kota Salatiga), adalah sebagai berikut :

1. Hasil uji hipotesis membuktikan bahwa Entrepreneurial Competencies berpengaruh terhadap Keunggulan Bersaing, dengan didapat hasil uji $-\mathrm{t}$ sebesar $-0,347$ dengan sig. $0,731>\alpha=0,05$. Berdasarkan dari hasil yang didapat ini dapat ditarik kesimpulan bahwa adanya peningkatan pada Entrepreneurial Competencies yang ditunjukkan pelaku usaha konveksi maka akan semakin menurunkan Keunggulan Bersaing Pelaku Usaha Konveksi Kota Salatiga.

2. Hasil uji hipotesis membuktikan bahwa Keunggulan Bersaing berpengaruh terhadap Kinerja Wirausaha, dengan didapat hasil uji $-\mathrm{t}$ sebesar 5,670 dengan sig. 0,000 $<\alpha=0,05$. Berdasarkan dari hasil yang didapat ini dapat ditarik kesimpulan bahwa adanya pelaksanaan Keunggulan Bersaing yang lebih baik, maka akan semakin meningkatkan Kinerja Wirausaha pada pelaku usaha konveksi Kota Salatiga.

3. Hasil uji hipotesis membuktikan bahwa Entrepreneurial Competencies berpengaruh terhadap Kinerja Wirausaha, dengan didapat hasil uji $-\mathrm{t}$ sebesar 0,003 dengan sig. 0,998 $>\alpha=0,05$. Berdasarkan dari hasil yang didapat ini dapat ditarik kesimpulan bahwa adanya peningkatan Entrepreneurial Competencies yang dilakukan oleh pelaku usaha konveksi, maka akan semakin menurunkan Kinerja Wirausaha pelaku usaha konveksi KUBE Maju Bersama Kota Salatiga.

4. Hasil analisis jalur memperlihatkan bahwa pengaruh tidak langsung Entrepreneurial Competencies terhadap Kinerja Wirausaha melalui Keunggulan Bersaing lebih kecil dibanding pengaruh langsung Entrepreneurial Competencies terhadap Kinerja Wirausaha. Dengan hasil ini maka dapat disimpulkan Keunggulan Bersaing tidak dapat menjadi variabel yang memediasi antara Entrepreneurial Competencies terhadap Kinerja Wirausaha atau adanya Entrepreneurial Competencies dalam berwirausaha tidak akan menumbuhkan Keunggulan Bersaing dalam berwirausaha.

\section{DAFTAR PUSTAKA}

Bartlett, C.A. and Ghoshal, S. (1997), "The myth of the generic manager: new personal competencies for new management roles", California Management Review, Vol.40 No.1 pp. 92-116.

Basu, A and Goswami, A (1999), "South Asian entrepreneurship in Great Britain: factors influencing growth", International Journal of Entrepreneurial Behaviour \& Research Vol.5 No.5, pp. $251-275$.

Baum, J.R. (1994), "The relationship of traits, competencies, motivation, strategy and structure to venture growth", $\mathrm{PhD}$ dissertation, University of Maryland, MD, USA.

Baum, J. R., Locke, E. A., and Smith, K. G. (2001). "A multidimensional model of venture growth", Academy of Management Journal. Vol. 44, No. 2, pp.292-303

Bird, B. (1993), "Demographic approaches to entrepreneurship: the role of experience and background", Advances to in Entrepreneurship, Firm Emergence, and Growth, Vol.1 pp.11-48

Bird, B. (1995), "Towards a theory of entrepreneurial competency", Advances in Entrepreneurship, Firm Emergence and Growth, Vol. 2, 51-72.

Boyatzis, R.E. (1982), The Competent Manager: A Model for Effective Performance, Wiley, New York.

Churchill, N.C. and Lewis, V.L. (1983), "The five stages of small business growth", Harvard Business Review Vol.61 No.3, pp.1-12.

Colombo, M. G. and Grilli, L. (2005), "Founders' human capital and the growth of new technology-based firms: a competencebased view", Research Policy, Vol.34 No.6, pp.795-816.

Freel, M. S, (1999), "Where are the skills gaps in innovative small firms?", International Journal of Entrepreneurial Behaviour \& Research, Vol 5

No.3, pp.144-154 Gabrielsson, J and J, Tell. (2009), Managerial learning and development in small firms: implications based on observations of managerial work, CIRCLE, Lund University,Sweden.

Gabraith, J R (1982), "Stages of business growth", Journal of Business Strategy, Vol. 3 No.4, pp.70-79.

Jogiyanto. 2004. Metode Penelitian Bisnis : Salah Kaprah dan Pengalaman- Pengalaman. Edisi 2004/2005. BPFE. Yogyakarta. 
Hayton, J. C. and Kelley, D. J. (2006), “A competency-based framework for promoting corporate entrepreneurship", Human Resource Management, Vol.45 No.3, pp. 407-427.

Hayton, J. C. and McEvoy, M. (2006), “Guest editor's note”, Human Resource Management, Vol.45 No.3, pp.291-294.

Herron, L. and Robinson, R.B. (1993), "A structural model of the effects of entrepreneurial characteristics on venture performance", Journal of Business Venturing,Vol.8 No.3, pp.281-294.

Man, T.W.Y. and Lau T. (2005), "The Context of entrepreneurship in Hong Kong”,Journal of Small Business and Enterprise Development, Vol. 12 No.4, pp.464-481.

Man, T., Lau, T. and Chan, K. F. (2002), "The competitiveness of small and medium enterprises. a conceptualisation with focus on entrepreneurial competencies". Journal of Business Venturing. Vol. 17 No.2, pp.123-142.

Man, T, and T. Lau. (2000), "Entrepreneurial competencies of SME owner/managers in the Hong Kong services sector: a qualitative analysis", Journal of Enterprising Culture Vol. 8, No.3, pp. 235-54.

Mitchelmore,S. and Rowley,J.(2010). Entrepreneurial Competencies: A Literature Review and Development Agenda. Emerald Group Publishing.

Riduwan dan Engkos Achmad Kuncoro. 2008. Cara Menggunakan Dan Memakai Analisis Jalur (Path Analysis)". Cetakan Kedua. Alfabeta. Bandung.

Rizky M. (2015), “Analisis pengaruh kompetensi wirausaha dan kemampuan mengindera pasar terhadap keunggulan bersaing untuk meningkatkan kinerja pemasaran (studi kasus pada UMKM Kota Semarang)"

Sugiyono, 2000. Metode Penelitian, Bandung : CV Alfabeta

Suryana. 2003. Kewirausahaan: Pedoman Praktis, Kiat dan Proses Menuju Sukses. Jakarta: Salemba Empat 